con diabetes materna es la macrosomía, y se sabe que habitualmente la exposición intrauterina a un medio hiperglucémico incrementa el riesgo y programación en la descendencia para desarrollar diabetes y/u obesidad más tarde en la vida adulta. Esta "programación fetal" ocasionada por un entorno diabético se denomina "memoria metabólica". Además existe evidencia que la obesidad materna también puede incrementar el riesgo de obesidad y diabetes en la descendencia. Sin embargo las mujeres con diabetes gestacional probablemente tengan más riesgo de macrosomía en la descendencia. Obesidad y diabetes en el embarazo tienen efectos independientes y aditivos.

A pesar de todo, los mecanismos moleculares a través de los cuales la exposición a un medio ambiente uterino alterado se traduce en el desarrollo de enfermedades crónicas no son todavía del todo comprendidos. Reportes recientes sugieren que las modificaciones epigenéticas son un potencial mecanismo para la mala programación metabólica fetal.

En la actualidad existen pocos estudios a nivel molecular en humanos para corroborar la teoría de la epigenética en la programación metabólica fetal. Diversos estudios en placentas de madres con diabetes demostraron modificaciones en la metilación del ADN de ciertos genes, como los de leptina y adiponectina. Estas alteraciones epigenéticas son principalmente funcionales y tendrían efectos a largo plazo en la regulación del metabolismo energético de la descendencia.

Sin lugar a dudas el próximo paso será estudiar en forma prospectiva grandes poblaciones, desde la concepción hasta la vida adulta, y diseñar estudios randomizados en los cuales las mujeres con riesgo de desarrollar DG puedan tener acceso a programas de prevención previo a la gesta o al menos no más allá de la finalización del primer trimestre del embarazo, para probar que las modificaciones epigenéticas que se producen en la DG y en la obesidad son las responsables de la programación metabólica fetal.

\title{
BIBLIOGRAFÍA
}

-Taylor PD. Developmental programming of obesity in mammals. Exp Physiol 2007; 92:287-291.

- Barker DJ, Hales CN, Fall CH, Osmond C, Phipps K, Clark PM. Type 2 (non-insulin-dependent) diabetes mellitus, hypertension and hyperlipidaemia (syndrome X): relation to reduced fetal growth. Diabetologia 1993; 36:62-67.

- Hales CN, Barker DJ. Type 2 (non-insulin-dependent) diabetes mellitus: the thrifty phenotype hypothesis. Diabetologia 1992; 35:595-601.

- William L, Lowe Jr, et al.; for the HAPO Follow-up Study Cooperative Research Group. Association of gestational diabetes with maternal disorders of glucose metabolism and childhood adiposity. JAMA 2018; 320(10):1005-1016. Doi:10.1001/ jama.2018.11628.

\section{Lactancia materna}

Dra. Gabriela Krochik

En la actualidad existe un importante cuerpo de evidencia que sostiene que diferentes factores nutricionales y metabólicos, que actúan en períodos sensibles y limitados del desarrollo humano temprano, tienen efectos "programadores" de la salud, el bienestar y el rendimiento a largo plazo que se extienden hasta la adultez y la edad mayor.

La nutrición, en particular la de los primeros meses de la vida, demostró tener enormes y poderosos efectos al ofrecer oportunidades tempranas para la prevención y promoción de la salud de la población a largo plazo.

La lactancia materna provee una nutrición óptima para los lactantes, con efectos positivos en su salud, lo que permite un crecimiento y desarrollo ideales.

Por este motivo, la Organización Mundial de la Salud (OMS) recomienda lactancia exclusiva los primeros seis meses de vida para todos los niños. El tiempo durante el cual se recomienda continuar la misma depende de las características económicas de la población: 12 meses o más para poblaciones de países industrializados y 24 meses o más para poblaciones con altas tasas de enfermedades infecciosas dado que el amamantamiento mostró disminuir la morbimortalidad en los primeros años de vida ${ }^{1}$.

Desde el punto de vista de la composición corporal, los niños amamantados exclusivamente los primeros seis meses de vida son más delgados en los primeros 12 meses. Este patrón diferencial de crecimiento se relaciona a largo plazo con menor riesgo de obesidad². 
Además de los efectos tempranos sobre los niños, la lactancia materna manifestó efectos positivos sobre la salud materna: induce la utilización de los depósitos grasos corporales al reducir el sobrepeso materno, y disminuye el riesgo de cáncer de mama y ovario, de diabetes mellitus tipo 2 (DM2) y artritis reumatoidea.

A largo plazo el amamantamiento demostró, en numerosos estudios longitudinales, disminuir, en las personas amamantadas, el riesgo de obesidad, hipertensión arterial, DM2 y dislipemias ${ }^{3}$.

\section{BIBLIOGRAFÍA}

1. Section on breastfeeding. Breastfeeding and the use of human milk. Pediatrics 2012; 49: 112-125.

2. Koletzko B, Chourdaris M, Grote V, Hellmuth C, Prell C, Rzehak P, Uhl O, Weber M. Regulation of early human growth: impact on long term health. Ann Nutr Metab 2014; 65: 101-109.

3. Horta BL, Victora C. Long term effects of breastfeeding: a systematic review. Geneve. WHO, 2013. Disponible en: http:// apps.who.int/iris/bilstream/10665/79198/1/9789241505307_eng.pdf.

\section{Microbiota}

Dr. Gustavo Frechtel

La microbiota intestinal se considera un órgano que posee un importante impacto en la salud del huésped, cuya formación en los dos y tres primeros años de vida es clave en el futuro desarrollo de la salud/enfermedad del individuo.

En el período perinatal los niños son colonizados con microbiota intestinal que depende del ambiente que los rodea y de las características del propio huésped para alcanzar una comunidad de bacterias intestinales específica e individual, que impactará en su salud a lo largo de su vida.

Esta microbiota temprana se reconoce como un importante factor para la salud humana a largo plazo dado que posee un rol central en dirigir el desarrollo del sistema inmune, así como el programming metabólico.

Tradicionalmente se sostiene que la colonización de bacterias en el intestino del neonato comienza con el nacimiento, pero recientes publicaciones afirman que ocurre desde el útero lo cual desafía la teoría de la esterilidad uterina.

Al nacimiento la microbiota del neonato se asemeja a la composición bacteriana de la vagina y de la piel de la madre, dependiendo si el parto fue por vía vaginal o por cesárea. Luego, la inmediata futura formación de la microbiota en el neonato dependerá del tiempo de lactancia materna, el tipo de alimentación o el uso de antibióticos, entre los factores más importantes. Otro tipo de influencia significativa es el ambiente hospitalario en aquellos niños que nacen pre-término y permanecen un largo período de tiempo hospitalizados.

En una reciente publicación el peso de la madre pre-embarazo correlacionó positivamente con el peso del neonato al año de nacido; en esa misma publicación se demostró que las madres obesas presentaron menor tiempo de lactancia que las madres con peso normal. Aquellos niños con un mayor período de lactancia cercano al año mostraron una microbiota intestinal más diversa que quienes recibieron lactancia materna por menos de seis meses. La diversidad en la composición de la microbiota intestinal correlaciona con un metabolismo más saludable en el huésped.

El peso de la madre pre-embarazo correlaciona con el tipo de microbiota intestinal y a su vez esta composición correlaciona con la del neonato, comprobándose una transmisión transgeneracional de la microbiota intestinal.

Es indudable la influencia de la microbiota intestinal en el desarrollo de obesidad, enfermedad metabólica y diabetes, por lo tanto, el conocimiento de la composición temprana de la microbiota intestinal y los diversos factores que la afectan abre la perspectiva para desarrollar estrategias de intervención que tiendan restaurar la microbiota con el objetivo de mantener la salud metabólica del huésped. 